\title{
MONITORING ENGLISH SANDHI LINKING - A STUDY OF POLISH LISTENERS' L2 PERCEPTION
}

\section{GEOFFREY SCHWARTZ}

Adam Mickiewicz University in Poznań

geoff@wa.amu.edu.pl

ARKADIUSZ ROJCZYK

University of Silesia

arkadiusz.rojczyk@us.edu.pl

ANNA BALAS

Adam Mickiewicz University in Poznań

abalas@wa.amu.edu.pl

\begin{abstract}
This paper presents a set of word monitoring experiments with Polish learners of English. Listeners heard short recordings of native English speech, and were instructed to respond when they recognized an English target word that had been presented on a computer screen. Owing to phonological considerations, we compared reaction times to two types of vowel-initial words, which had been produced either with glottalization, or had been joined via sandhi linking processes to the preceding word. Results showed that the effects of the glottalization as a boundary cue were less robust than expected. Implications of these findings for models of L2 speech are discussed. It is suggested that the prevalence of glottalization in L1 production makes listeners less sensitive to its effects as a boundary cue in L2.
\end{abstract}

\section{Introduction}

In recent years, research in second language (L2) speech acquisition has started to devote more attention to external sandhi - phonological processes that span word boundaries. Studies by Cebrian (2000), Zsiga (2003, 2011), Lleo and Vogel (2004), Altenberg (2005), Ito and Strange (2009), Bissiri, Lecumberri, Cooke, and Volín (2011), Volín, Uhrinová, and Skarnitzl (2012), Šimáčková, Kolářová, and Podlipský (2014), Schwartz, Balas, and Rojczyk (2014), and Shoemaker (2014), along with a larger body of work on the acquisition of the well-known processes of liaison and enchainement in L2 French, (e.g. Howard, 2006; Howard, 2008; Sturm, 2013; Shoemaker, 2010), indicate that L2 research has started to move beyond simple segmental features such as vowel quality and Voice Onset Time (VOT). This research has included studies of how L2 learners acquire boundary effects in the target language, as well as the degree to which learners suppress L1 boundary effects in the process of L2 acquisition. 
In the findings of L2 sandhi research so far, it is difficult to identify commonalities. In some cases, acquisition of sandhi processes has been successful, while in others it has been less so. For example, Shoemaker (2010) found that advanced L1 English learners of French performed at near ceiling levels in the perception of the fine phonetic details French speakers use to distinguish boundary 'minimal pairs' (un air $\sim$ un nerf 'a melody' $\sim$ 'a nerve') with identical segmental content that differ solely with respect to the boundary location. Similar research with English as an L2 has shown that Spanish (Altenberg, 2005), Japanese (Ito \& Strange, 2009), and French (Shoemaker, 2014) have less success in distinguishing pairs like keeps talking $\sim$ keep stalking than pairs such as $a$ nice man an ice man. With regard to the suppression of L1 boundary effects in L2 production, some works (Cebrian, 2000; Lleo \& Vogel, 2004) have noted learner success in this area, while others (Zsiga, 2011; Schwartz et al., 2014) have found less encouraging results.

Since it has been difficult to draw unambiguous conclusions with regard to boundary phenomena, it appears as though predictions concerning L2 learners' performance with boundary effects require deep consideration of the particular process in question. In other words, we suggest that the phonological status of a given boundary effect in a given L1 should provide the greatest insight into the intricacies of L2 speech acquisition. If two different processes produce different results, the most natural conclusion is that these processes have a different phonological status. Our recent work (e.g. Schwartz et al., 2014; Rojczyk, Schwartz, and Balas, 2014; Balas, Schwartz, and Rojczyk, 2014) has explored the effects of glottal marking of word-initial vowels by Polish learners of English. In L1 Polish, glottalization is quite common, and prevents the kind of sandhi linking processes that are commonly observed in English, such as $\mathrm{C \# V}$ resyllabification, linking /r/, and linking glides (see e.g. Cruttenden, 2001). Thus, the failure to suppress glottal marking in the production of L2 English is an apparent obstacle to be overcome in the acquisition of English sandhi linking. Production studies have shown that (1) learners acquire linking processes later than other segmental features, (2) that more advanced learners are more successful in suppressing glottalization, (3) that advanced learners produce more glottalization in their L1 than in their L2, and (4) that explicit instruction in linking processes may be an effective part of pronunciation teaching. These findings are compatible with the claim that linking vs. glottalization is a significant phonological opposition in the two languages.

This paper describes Polish learners' perception of sandhi-linking vs. vowel glottalization in L2 English. A word monitoring task is used to investigate whether a target word is recognized more quickly if it is realized with glottalization. Surprisingly, the results of the studies suggest that the effects of glottalization for word recognition are minimal, despite the prevalence of glottalization in Polish and Polish-accented English. To interpret this result, we consider the hypothesis of 'desensitization' (Bohn, 1995), by which the role of L1 phonetic cues in L2 perception is minimized. The rest of this paper will proceed as follows. Section 2 will present further background on L2 sandhi research, as well as vowel glottalization in Polish and English. Section 3 describes the experiment. Section 4 discusses the implications of our findings for theoretical models of second language speech. 


\section{Glottalization, linking and research into $\mathrm{L} 2$ boundary effects}

\subsection{The phonetics and phonology of glottal marking}

The empirical focus of this study is the realization of word-initial vowels in terms of glottalization vs. sandhi linking. In the production of vowels, speakers may produce an additional articulatory gesture in the larynx as a supplement to tongue and lip configurations. Laryngealization, or glottalization, may be observed in spectrograms as a period of silence associated with full glottal closure (glottal stops), or as a change in phonation type (voice quality), which is visible as a break in the regularity of the vocal wave. In addition, local drops in pitch and/or amplitude have been found to induce glottal stop percepts (Hillenbrand \& Houde, 1996). Glottalization in terms of voice quality is illustrated in Figure 1, which shows a production of the Polish phrase brata Artura 'Arthur's brother'. In the spectrogram, glottalization is visible as the vertical lines interrupting the $/ \mathrm{a} \# \mathrm{a} /$ sequence.

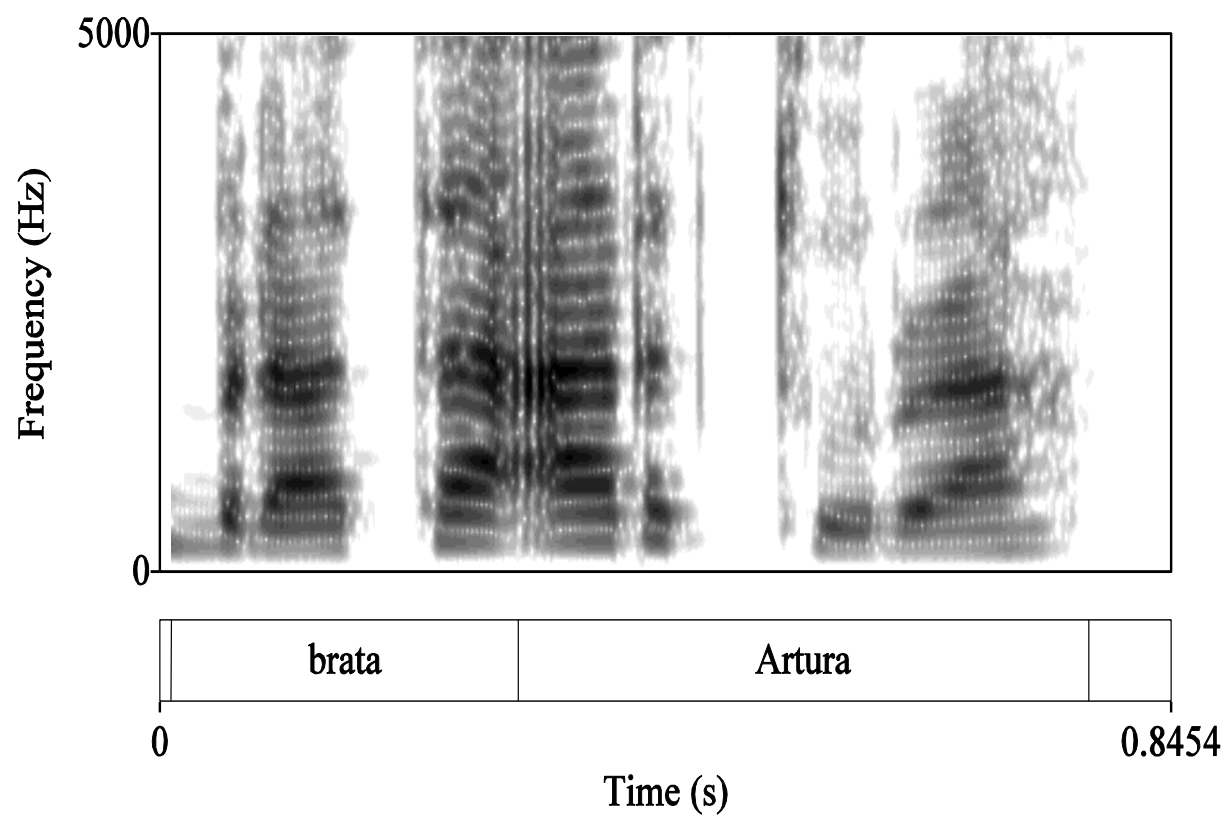

Figure 1. spectrogram of Polish brata Artura 'Arthur's brother' with glottalization.

A common claim found in studies on vowel glottalization is that the phenomenon is a kind of 'universal phonetic default' (Ratcliffe, 1996; cited in Altenberg, 2005, p. 345), used to mark boundaries, that is also common in English. As a 'universal default', the phonological status of vowel glottalization is therefore implicitly assumed to be largely equivalent in languages without phonemic glottal stops. However, there is reason to suggest that its characterization as a universal phonetic phenomenon is in need of further 
refinement. Word-initial vowels in English are frequently susceptible to linking processes (e.g. Cruttenden, 2001), including resyllabification (find out $\sim$ fine doubt) linking or intrusive $/ \mathrm{r} /$, as well as glide-like transitions (two eyes $\sim$ too wise). ${ }^{1}$ An illustration of linking is shown in Figure 2, depicting the English phrase do it, which appears on the spectrogram to contain a single portion of vocalic material. The 'boundary' between the two words is not marked.

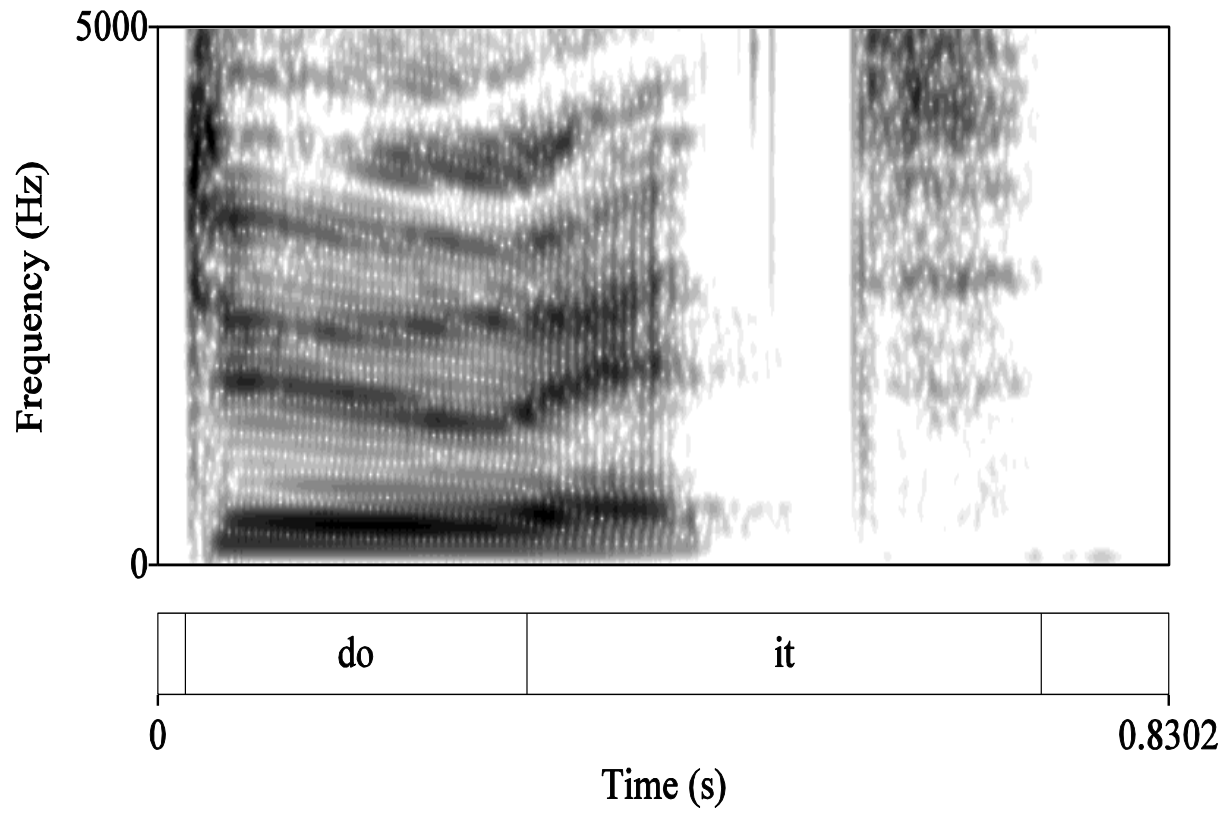

Figure 2. Spectrogram of English do it with linked realization.

The example suggests that glottalization is not a 'default' for English. Rather, its use tends to be limited the marking of phrase-level boundaries and prominent syllables (Dilley, Shattuck-Hufnagel, \& Ostendorf, 1996; Garellek, 2012), while linking is the norm phrase-medially. ${ }^{2}$ This contrasts with languages such as German (Wiese, 1996), Czech (Palková, 1997) or Polish (Schwartz, 2013a), in which vowel glottalization is

\footnotetext{
${ }^{1}$ Davidson and Erker (2014) provide evidence that so-called inserted glides are phonetically distinct from lexical glides. Thus, two eyes and too wise are not homophonous. However, in many previous descriptions of English, they had been perceived as homophonous when the vowel-initial word was not glottalized. Although Davidson and Erker suggest that glottalization is an alternative to 'glide insertion', in their data most of the stimulus items were stressed initial vowels, which Garellek (2012) found to be particularly susceptible to glottalization.

${ }^{2}$ A reviewer raises the possible example of Anna Aldridge, in which a glottal stop may appear phrase medially, as a challenge to our claim. In the example the reviewer mentions, the initial vowel that receives glottal marking bears word stress, which is of course covered by the phrase 'prominent syllables' that is included in our formulation of the claim. Stress has been found to be a contributing factor to glottalization in English (Garellek, 2012).
} 
common phrase-medially and even word-medially, and blocks the type of linking processes found in French and English. In rapid speech, in which glottalization is less likely, Polish tends to preserve the prominence of the word-initial vowel. Thus, instead of linking the $\mathrm{V \# V}$ sequence in czy Agnieszka 'or Agnieszka', in rapid speech Polish speakers have a tendency to elide the first vowel and produce cz'Agnieszka, thus preserving the initial vowel at the expense of the final vowel (see Schwartz, 2013a).

In sum, Polish and English appear to show a categorical opposition with regard to the realization of initial vowels. In Polish, the 'initial' status of the vowel is preserved, and is frequently reinforced by glottalization. In English, initial vowels are susceptible to linking processes, and may lose their 'initial' status. Glottalization may be used for emphasis, or to mark stressed initial vowels, or phrase boundaries. The phonological underpinnings of this opposition may be attributed to a parameter setting with regard to syllables lacking an onset consonant (see Schwartz, 2013b). ${ }^{3}$ In some languages, onsetless syllables show signs of prosodic deficiency, and are not counted for prosodic processes such as stress, reduplication, or tone. In others, onsetless syllables behave in a similar fashion to consonant-initial syllables. The parametric opposition may be seen in terms of an 'empty onset' that is present in Polish but absent in English.

\subsection{Glottalization in L2 studies}

Previous studies on glottalization production in L2 learners lend support to the phonological interpretation of the phenomenon. Whitworth (2003) examined prevocalic boundaries in the speech of German-English bilinguals. Those for whom German was L1 for the most part did not suppress German-style glottalization. Schwartz et al. (2014) investigated the phonetic interaction between linking and final voicing in $\mathrm{CHV}$ sequences in Polish-accented English. They found a robust link between the suppression of glottalization and native-like production of final voiced obstruents. ${ }^{4}$ Final obstruent devoicing is an established feature of a Polish accent in English (Scheuer, 2003; Gonet $\&$ Pietroń, 2004). Since linking alters the 'final' status of word-final obstruents, its acquisition by Polish learners may be a pre-emptive step in avoiding final voicing errors. In another study, Šimáčková et al. (2014) looked at the production of linking vs.

\footnotetext{
${ }^{3}$ A reviewer suggests that more attention should be given to the clarification of the phonological underpinnings mentioned here. Since the goal of this paper is to present an experiment and not discuss phonological theory, the reviewer is referred to the cited literature. Stated briefly, our basic claim is that the term 'initial', which the reviewer takes for granted in his/her critique, is arbitrary as it is commonly in the mean of 'after a word boundary'. We suggest that the presence of word boundaries may in fact be predicted by phonological parameters that are not arbitrary, and that the relative robustness of linking processes reflects language-specific phonological considerations. That is, glottalization vs. linking is more than simply a phonetic opposition, even though it does not make reference to contrastive properties.

${ }^{4}$ A reviewer points out that final devoicing is also observable in native varieties of English. Native-like productions are those that maintain the laryngeal contrast (typically through durational parameters) even if vocal fold vibration ceases. However, in the cases described in this paper (i.e. before vowel initial words) devoicing is generally not observed if the $\mathrm{C \# V}$ sequence is linked.
} 
glottalization of vowel-initial words in Czech-accented English. They found that glottalization was quite common, but that linking could appear in faster utterances.

With regard to perception, a series of studies (Altenberg, 2005; Ito \& Strange, 2009; Shoemaker, 2014) has dealt with allophonic cues to boundaries in pairs of words with similar segmental sequences (a nice man an ice man). In addition to testing learners' ability to segment the speech stream in an L2, these studies have provided data on the relative salience of different types of boundary phenomena, including aspiration of initial stops (keeps talking vs. keep stalking) and glottalization of initial vowels. In each case, vowel glottalization has been found to be a more robust boundary cue than aspiration for non-native listeners. That is, Spanish listeners were more accurate in discriminating between a nice man from an ice man (with glottalization in the latter), then they were in pairs such as keeps talking keep stalking (with aspiration on the /t/ in talking). This finding has been reproduced for L1 Japanese listeners (Ito and Strange, 2009), and L1 French listeners (Shoemaker, 2014). Unfortunately, such boundary pair studies have been limited to L1s without the robust glottalization of the type found in German, Czech, or Polish.

While the boundary pair studies described above compare the effects of glottalization and aspiration with regard to boundary perception, they did not compare glottalized and linked tokens of initial vowels. Although we learned that glottalization is a more robust boundary cue than aspiration, the relative salience of glottalized vs. linked tokens was not tested. Another series of studies (Bissiri et al., 2011; Volín et al., 2012) has taken up this question explicitly. These studies used a word monitoring paradigm in which listeners were presented a target word on a computer screen accompanied by an audio recording. The task is to respond as soon as the target word is recognized. The analyzed data in these studies is response time. These studies compared L1 English, L1 Czech, L1 Spanish listeners. Native speakers, unsurprisingly, showed the quickest response times. For both Czech, Spanish, and Slovak listeners, response to glottalized items were shorter than to tokens without glottalization. In what follows, we will present a set of similar word monitoring experiments performed with Polish learners of English.

\section{Monitoring of linked vs. glottalized vowels}

This section describes the word monitoring experiments. The main research questions of our study are as follows:

- Does glottalization on initial vowels in L2 English lead to faster recognition of target words by Polish learners?

- Does level of proficiency in English, measured as year of study, interact with glottalization in determining reaction times to target words?

\subsection{Participants}

A total of sixty-three listeners participated in the experiment. All participants were pre-advanced and advanced Polish learners of English. Twenty participants were firstyear students of English recruited from the Institute of English, University of Silesia. 
Their proficiency of English was B2 in the Common European Framework of Reference for Languages (CEFRL). Another 20 participants were second-year students of English recruited from the Faculty of English, Adam Mickiewicz University in Poznan. Their proficiency was B2-C1 in the CEFRL. Finally, there were 23 third-year and fourth-year students of English recruited from the Faculty of English, Adam Mickiewicz University in Poznan with proficiency at C1-C2 in the CEFRL. None of the participants reported any hearing or manual disorders.

\subsection{Stimuli}

The stimuli consisted of 34 word-boundary sequences with both $\mathrm{C} \# \mathrm{~V}$ and $\mathrm{V} \# \mathrm{~V}$ combinations (Appendix). All initial vowels were stressed. The linked and glottalized tokens were selected from the corpus of recordings gathered for a larger project. Since the glottalized and linked versions of the same phrase were of different duration, the target words occurred at different time points in the experimental recordings. We decided not to time normalize them in PSOLA in order to preserve their authentic naturalness. Rather, we determined the time points at which the targets occurred and used them as benchmarks to calculate RTs. The target time points are given in Appendix. The experimental phrases were randomised and interspersed with 18 distractor phrases that were not included in the analysis.

\subsection{Procedure}

The experiment was run in E-Prime (Psychology Software Tools). First-year students were tested in the Acoustic-Phonetic Laboratory at the Institute of English, University of Silesia. Second-year, and third-year and fourth-year students were tested at the Faculty of English, Adam Mickiewicz University in Poznan. The participants were seated in front of a computer screen and listened to recordings of English sentences. They were instructed to respond when they heard a target word presented on the screen. They were encouraged to react as fast as they could. The experiment started with a welcome screen and the participants proceeded to the familiarization stage with five phrases not included in the analysis. Each trial started with a 'get ready' screen displayed for $2500 \mathrm{~ms}$ during which the participants set their finger on the 'space' button. Next the orthographic form of the target word was flashed in the middle of the screen for $1500 \mathrm{~ms}$. After that, the recording was played while the target word was still displayed on the screen. The target stimuli were blocked and counterbalanced for linked and glottalized sequences for each listener in order to avoid the carry-over order effect. Each experimental session lasted approximately 10 minutes. 


\subsection{Results}

RTs were calculated by subtracting the registered RTs from the target word onsets to determine the actual reaction to the target item in the recording. The obtained RTs were trimmed to reject responses below $100 \mathrm{~ms}$ and above $1000 \mathrm{~ms}$. Such trimming excluded false alarms and hesitations that resulted from conditions uncontrolled in the experiment (Bissiri et al., 2011).

The results pooled for all students without splitting into proficiency showed that target words in glottalizaed sequences $(M=398 ; S D=122)$ were recognized significantly faster than target words in linked sequences $(\mathrm{M}=411 ; \mathrm{SD}=129)[\mathrm{t}(1010)=-2.77, \mathrm{p}<.01$, $\mathrm{r}=.3]$.

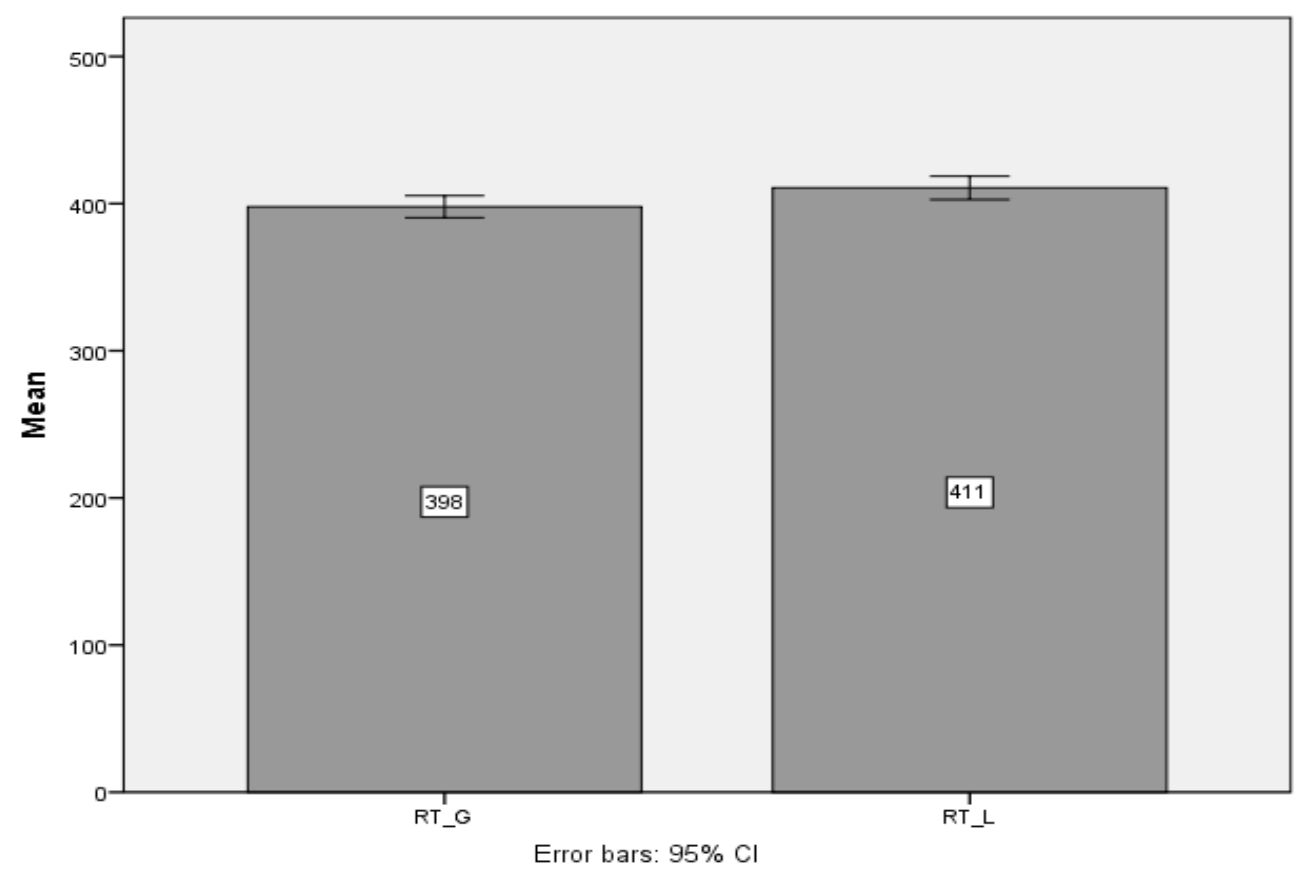

Figure 1. RTs for glottalized and linked tokens for all groups.

The analysis of RTs for the first-year students revealed that words at glottalized word boundaries were recognized faster $(M=390 ; S D=122)$ than words at linked word boundaries $(\mathrm{M}=409 ; \mathrm{SD}=131)[\mathrm{t}(360)=-2.56, \mathrm{p}<.05, \mathrm{r}=.4]$. 


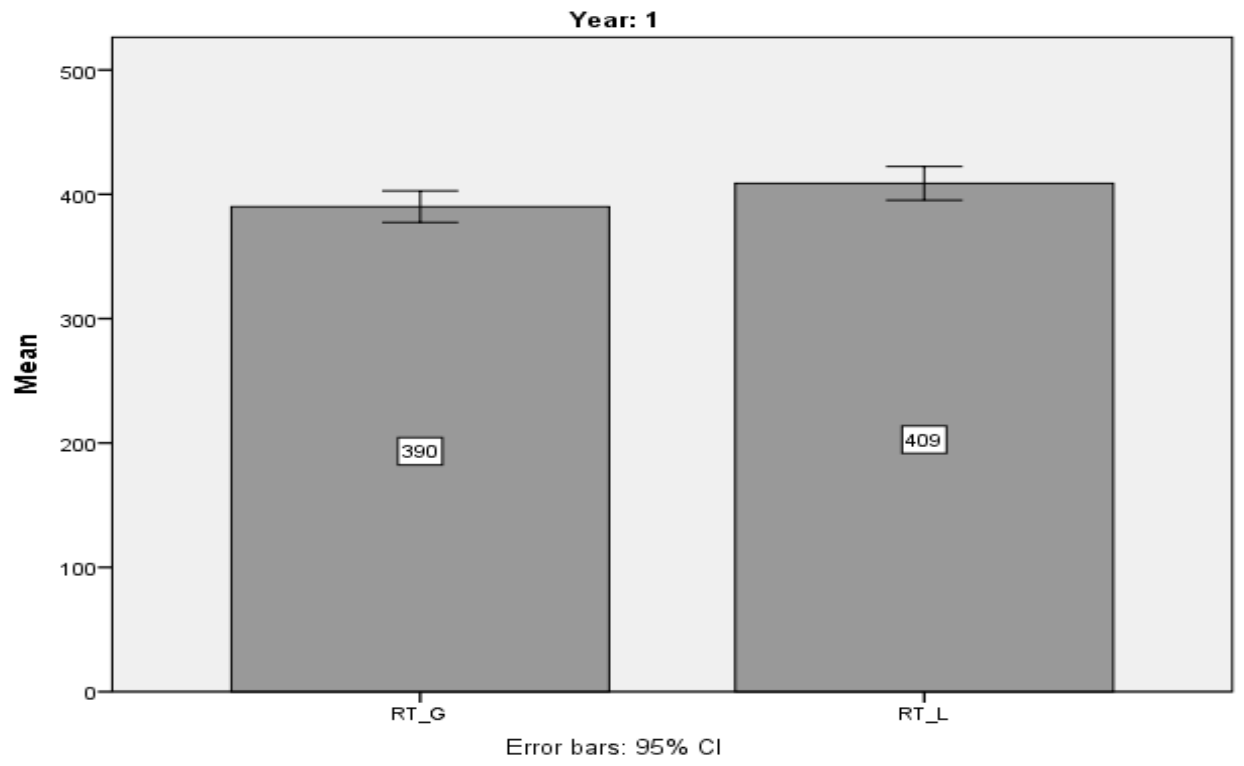

Figure 2. RTs for glottalized and linked tokens for first-year students.

In the group of second-year students the words at glottalized word boundaries were also recognized faster $(\mathrm{M}=409 ; \mathrm{SD}=416)$ than the words at linked word boundaries $(M=416 ; S D=141)$, however the difference was not significant $[t(296)=-.73, p>.05]$.

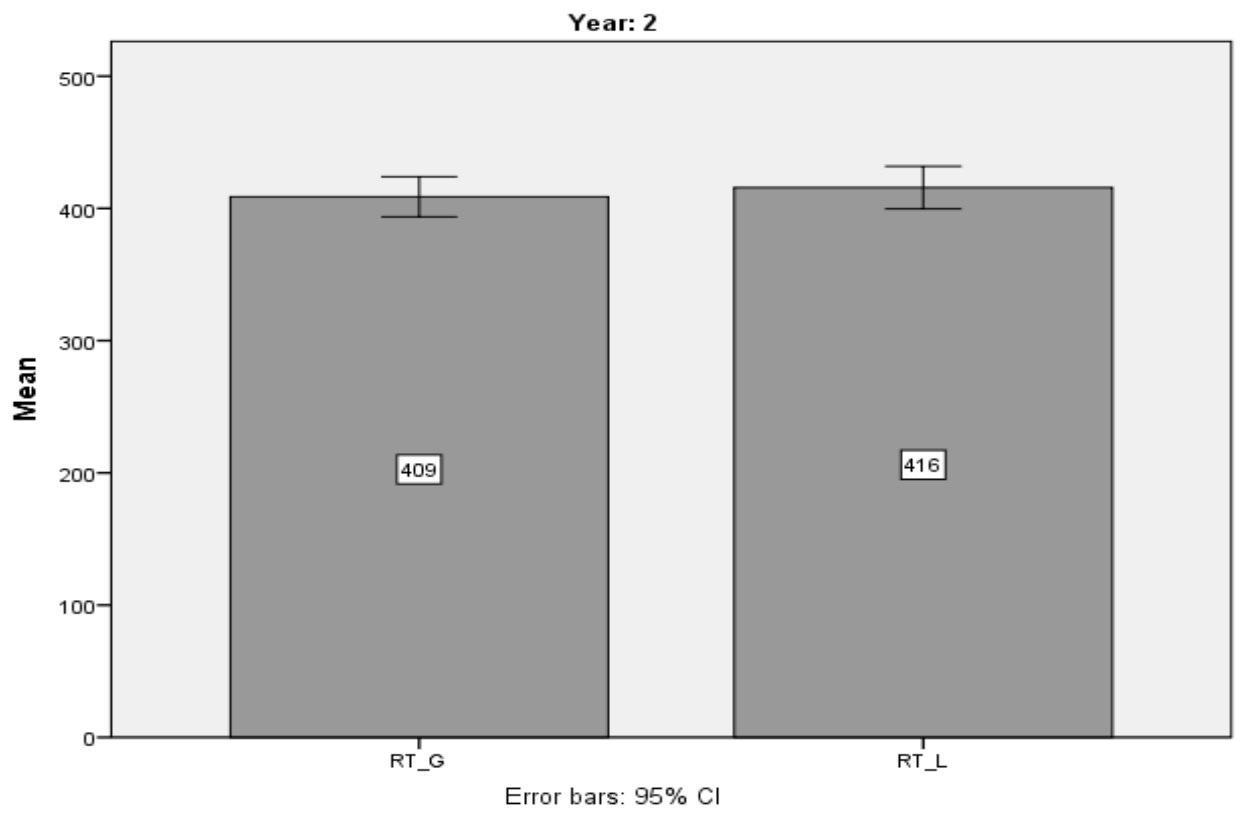

Figure 3. RTs for glottalized and linked tokens for second-year students. 
Similarly to the previous group, third- and fourth-year students also recognized glottalized words faster $(\mathrm{M}=397 ; \mathrm{SD}=112)$ than linked words $(\mathrm{M}=409 ; \mathrm{SD}=115)$, however the difference did not meet the criteria of significance $[\mathrm{t}(352)=-1.56, \mathrm{p}>.05]$.

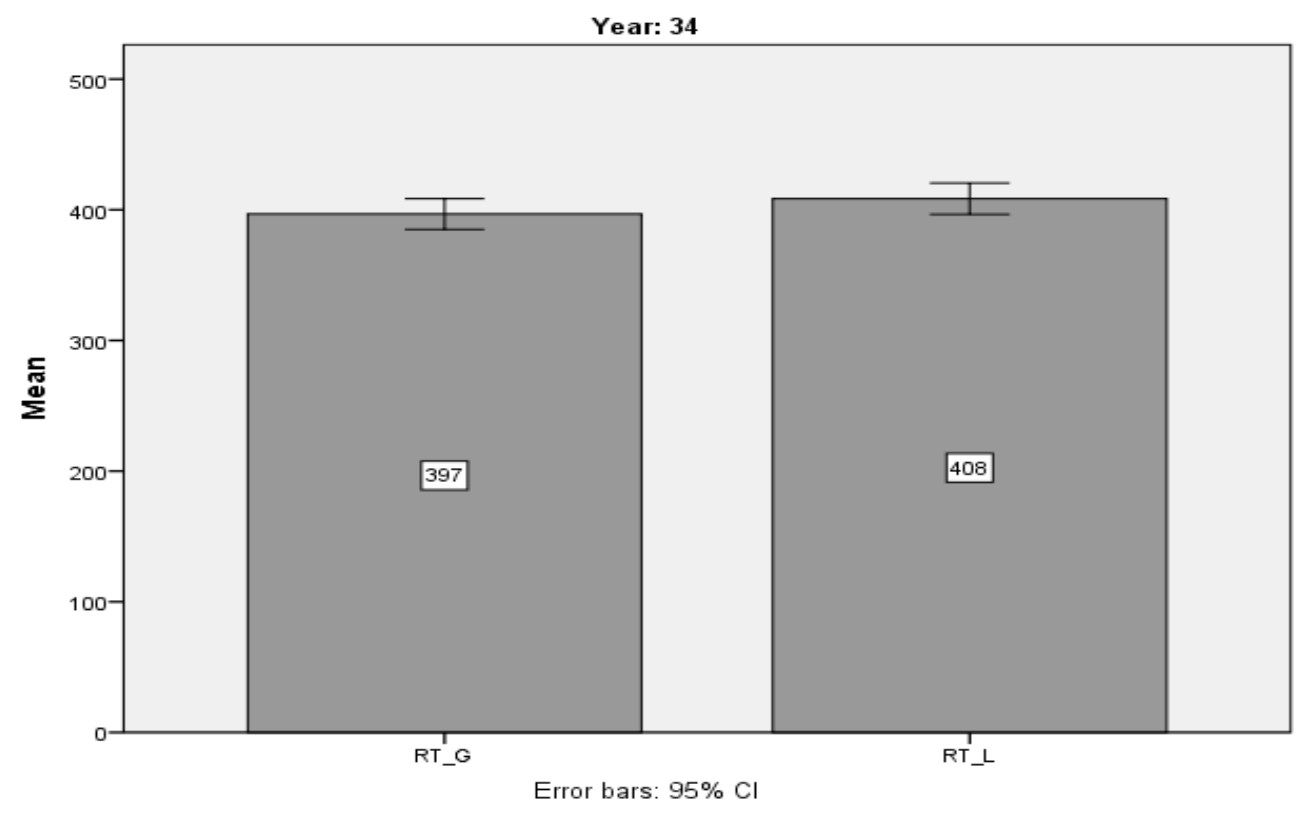

Figure 4. RTs for glottalized and linked tokens for third- and fourth-year students.

Finally, a mixed $3 \times 2$ ANOVA revealed no significant interaction between year of studies and boundary type, $[\mathrm{F}(2,1008)=.54, \mathrm{p}=0.58]$. This result is depicted graphically in Figure 5. 


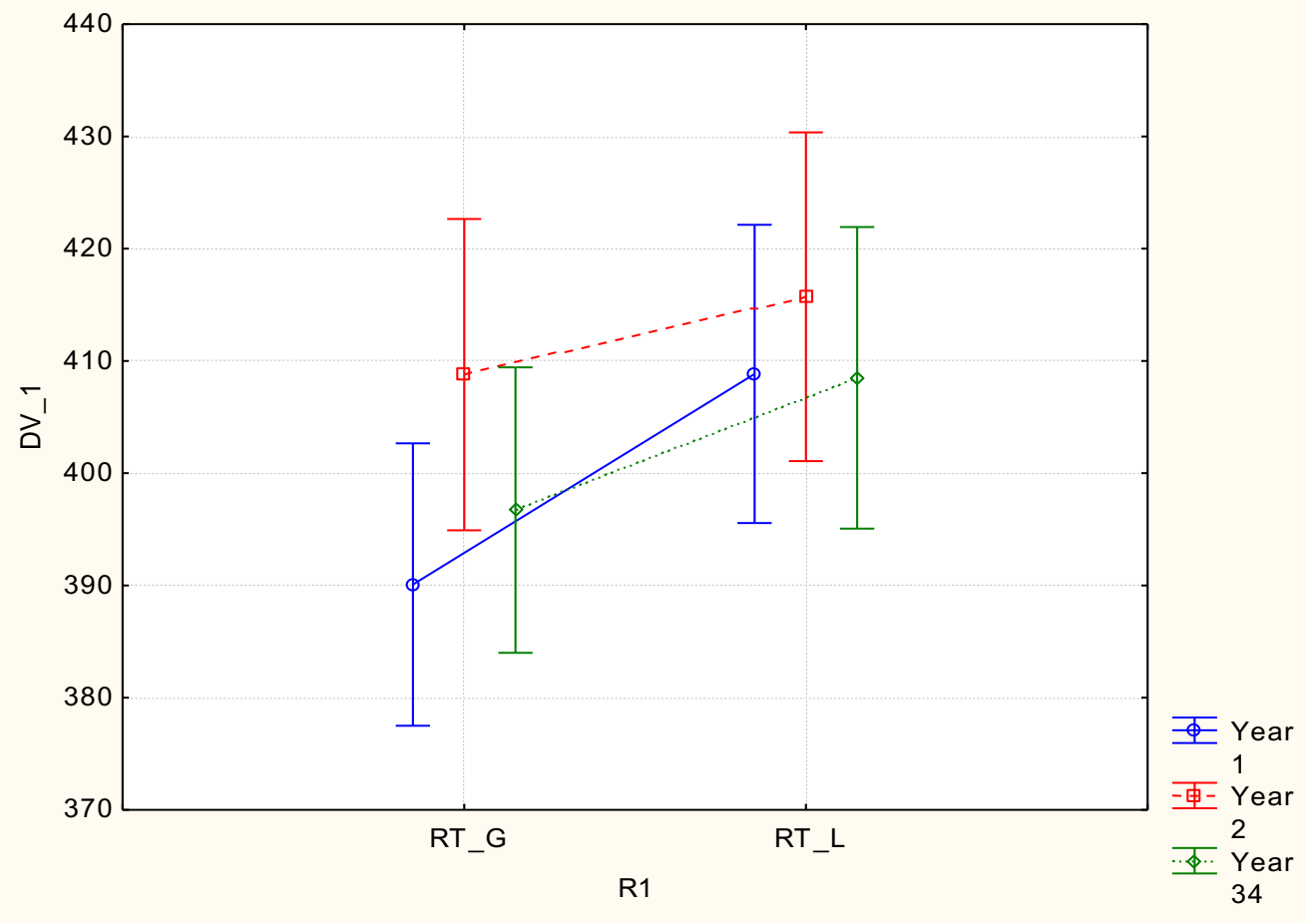

Figure 5. RTs for glottalized and linked tokens for first-, second-, third- and fourth-year students.

\subsection{Discussion}

The results of the experiments may be summarized as follows. Glottalization was associated with a slight decrease in response times to the target words. This difference, however, was quite modest. Reaction times were on average less than $5 \%$ quicker in the case of glottalized items. The level of proficiency in English, measured in terms of year of studies in English philology programs at Polish universities, did not have a significant effect on the results. Although $1^{\text {st }}$ year students showed a significant difference in response times to the two types of stimulus, the statistical tests revealed that overall there was no significant interaction between the realization of the initial vowel and year of studies.

The overall pattern of these results strikes us as somewhat surprising. Considering the prevalence of glottalization in L1 Polish and in Polish-accented English, we expected it to play a more significant role in perception and lead to a larger decrease in response times across all groups of learners. This is what was found in other monitoring studies with Spanish, Czech and Slovak learners of English (Bissiri et al., 2011; Volín et al., 2012), in which glottalized tokens were recognized on average about $10 \%$ more quickly. Nevertheless, there were differences between this study and the other studies that may have contributed to the discrepancy in the results. Most importantly, the target words in this study all contained stressed initial vowels and were produced in relatively short utterances. These are contexts in which glottalization is likely to occur. By contrast, the stimuli in the other studies were taken from larger utterances extracted from radio news 
reports, and some of the tokens were function words that are less likely to be glottalized. Thus, the different contexts may have led to different expectations on the part of the listeners. Assuming that the stimuli differences may indeed explain the discrepancies in the results between the present study and those with learners of other languages, it may be hypothesized that glottalization provides a greater boost to word recognition in contexts in which it is less likely to appear. In the following section, we will consider the theoretical implications of this claim. Another possible interpretation of our results is that the participants in this study were simply 'too advanced', and were accustomed to hearing sandhi linking. To test this interpretation, we would need to run the monitoring experiments with native listeners. Unfortunately, in Poland it is difficult to gather an adequate group of experimental participants with English as their L1.

With regard to the differences in performance according to learner group, the results met our expectations in part. In particular, the contribution of glottalization to faster responses was greater for first year students than for higher level students. Assuming that higher level students have had more exposure to linking in L2, they should be less inclined to rely on glottalization for word recognition. One slightly unexpected finding was that independent of glottalization, overall response times did not decrease with higher levels of proficiency. One would think that more advanced learners should have recognized target words more quickly. They did not. A possible contributing factor might be that the first year group, in which student enthusiasm levels are higher, took a more serious approach to the experiment. Another possibility is that since the target words were relatively basic, they were already sufficiently familiar to all university-level students. Future work will need to test lower-level learners that learners at the primary or secondary school level.

\section{Equivalence and desensitization in $L 2$ perception}

One of the more well-established concepts in the L2 speech literature is that of 'equivalence classification' (Flege, 1987), which is claimed to govern the success of speech learning as a function of the phonetic similarity of phonetic categories in L1 and L2. When an L1 and L2 sound are deemed phonetically similar, learners do not 'acquire' that sound as a new phonetic category. Rather, they treat it as a realization of the closest sound in their own L1 system. As an example, Flege (1987) cites L1 English learners' acquisition of the contrast between $/ \mathrm{u} /$ and $/ \mathrm{y} /$ in French. Since the $/ \mathrm{y} /$ is a 'new' sound for English speakers, learners eventually acquire it and produce it accurately. The French /u/, however, appears to be categorized as a token of English /u:/, which is nevertheless produced with a more fronted tongue position than the French vowel. Because of equivalence classification, L1 English learners tend not to produce the French vowel with a low enough F2 indicative of the target language /u/. One essential aspect of equivalence classification is that if an L2 phonetic feature is familiar from L1, learners may resist adopting it directly into their $\mathrm{L} 2$ system.

This basic concept may also be said to underlie Bohn's (1995) 'desensitization' hypothesis. Bohn sought to interpret findings from L2 perception studies. In one case, Spanish L1 speakers discriminated selected English vowel contrasts on the basis of duration cues, despite the fact that vowel duration is not available as a cue for L1 vowel 
contrasts. Bohn suggested that listeners may be desensitized by their coarse-grained L1 spectral contrasts, and have difficulty adapting the perception of spectral properties to the L2 vowel system in which the contrasts are more subtle. Duration, a new cue that is outside their L1, rather than formant patterns, therefore becomes active in L2 perception even though it is absent from L1. We suggest that the modest effects of glottalization in the word monitoring tasks of the present study may be explained in similar terms. Since glottalization is quite common in L1 Polish, and the contexts of the stimuli were such that listeners may have expected glottalization, the Polish participants may have been desensitized to its effects as a boundary cue. In other words, since glottalization was expected, it may have been perceptually transparent to the Polish listeners. If this interpretation is correct, we might hypothesize the existence of an inverse relationship between the likelihood of glottalization in production and its effects as a boundary cue in perception. This hypothesis should be explored in future research.

To conclude, this paper has added to the body of literature on the perception of boundary effects in a second language. The somewhat surprising result suggests the need for further research, but is nevertheless interpretable within the context of current theoretical models of L2 speech acquisition. Interestingly, this interpretation lends support to the general notion that phonetic features that are familiar from L1 may be a handicap to L2 acquisition.

\section{Acknowledgement}

This research was supported by a grant from the Polish National Science Centre (Narodowe Centrum Nauki), project nr. UMO-2012/05/B/HS2/04036, "Sandhi in second language speech". 


\section{References}

Altenberg, E. (2005). The perception of word boundaries in a second language. Second Language Research, 21(4), 325-358.

Balas, A., Schwartz, G., \& Rojczyk, A. (2014). Explicit instruction in boundary liaison benefits for the production of final voiced obstruents in L2 English. Paper given at the 47th Annual Meeting of Societas Linguistica Europea, Poznań.

Bissiri, M. P., Lecumberri, M. L., Cooke, M., \& Volín, J. (2011). The role of wordinitial glottal stops in recognizing English words. Proceedings of Interspeech 2011. Florence, Italy.

Bohn, O-S. (1995). Cross-language speech perception in adults - first language transfer does not tell it all. In W. Strange (Ed.), Speech perception and linguistic experience: Issues in cross-language research (pp. 275-300). Baltimore: York Press.

Cebrian, J. (2000). Transferability and productivity of L1 rules in Catalan-English interlanguage. Studies in Second Language Acquisition, 22, 1-26.

Cruttenden, A., (2001). Gimson's Pronunciation of English (6th ed.). London: Arnold.

Davidson, L., \& Erker, D. (2014). Hiatus resolution in American English: the case against glide insertion. Language, 90(2), 482-514.

Dilley, L., Shattuck-Hufnagel, S., \& Ostendorf, M. (1996). Glottalization of word-initial vowels as a function of prosodic structure. Journal of Phonetics, 24, 423-444.

Flege, J. E. (1987). The production of 'new' and 'similar' phones in a foreign language: evidence for the effect of equivalence classification. Journal of Phonetics, 15, 47-65.

Garellek, M. (2012). Word-initial glottalization and voice quality strengthening. UCLA Working Papers in Phonetics, 111, 92-122.

Gonet, W., \& Pietroń, G. (2004). The Polish tongue in the English ear. In W. Sobkowiak \& E. Waniek-Klimczak (Eds.), Zeszyty Naukowe PWSZ w Koninie (pp. 56-65). Konin: Wydawnictwo PWSZ.

Hillenbrand, J. M., \& Houde, R.A. (1996). The role of F0 and amplitude in the perception of intervocalic glottal stops. Journal of Speech and Hearing Research, 39, 1182-1190.

Howard, M. (2006). Variation in advanced French interlanguage: A comparison of three (socio) linguistic variables. The Canadian Modern Language Review/La revue canadienne des langues vivantes, 62(3), 379-400.

Howard, M. (2008). On the role of naturalistic and classroom exposure in the acquisition of socio-phonological variation: A longitudinal study of French liaison. Journal of Applied Linguistics, 5(2), 159-179.

Ito, K., \& Strange, W. (2009). Perception of allophonic cues to English word boundaries by Japanese second language learners of English. Journal of the Acoustical Society of America, 125(4), 2348-2360.

LLeo, C., \& Vogel, I. (2004). Learning new segments and reducing domains in German L2 phonology: The role of the Prosodic Hierarchy. International Journal of Bilingualism, 8, 79-104.

Palková, Z. (1997). Fonetika a fonologie češtiny. Praha: Karolinum.

Ratcliffe, R. (1996). Languages with obligatory onsets and without distinctive length. Message posted to LINGUIST List electronic mailing list, archived at: http://linguistlist.org/issues/7/7-1698.html\#1 . 
Rojczyk, A., Schwartz, G., \& Balas, A. (2014). The production of word-boundary C\#V sequences by Polish learners. Paper given at the 6th Annual PSLLT Conference. Santa Barbara, CA.

Scheuer, S. (2003). What to teach and what not to teach? Some reflections on the relative salience of interlanguage errors. In W. Sobkowiak \& E. Waniek-Klimczak (Eds.), Zeszyty Naukowe PWSZ w Koninie (pp. 93-99). Konin: Wydawnictwo PWSZ.

Schwartz, G. (2013a). Vowel hiatus at Polish word boundaries - phonetic realization and phonological implications. Poznań Studies in Contemporary Linguistics, 49(4), 557585.

Schwartz, G. (2013b). A representational parameter for onsetless syllables. Journal of Linguistics, 49(3), 613-646. DOI: http://dx.doi.org/10.1017/S0022226712000436.

Schwartz, G., Balas, A., \& Rojczyk, A. (2014). External sandhi in L2 segmental phonetics - final (de)voicing in Polish English. Concordia Working Papers in Applied Linguistics 5, 637-649.

Shoemaker, E. (2010). The exploitation of fine phonetic detail in the processing of L2 French. In B. Van Patten \& J. Jegerski (Eds.), Research in Second Language Processing and Parsing (pp. 259-279). Amsterdam : John Benjamins.

Shoemaker, E. (2014). The exploitation of subphonemic acoustic detail in L2 speech segmentation. Studies in Second Language Acquisition, 36(4), 709-731.

Šimáčková, Š., Kolářová, K., \& Podlipský, V. J. (2014). Tempo and connectedness of Czech-accented English speech. Concordia Working Papers in Applied Linguistics, 5, 667-677.

Sturm, J. (2013). Liaison in L2 French: The effects of instruction. In J. Levis \& K. LeVelle (Eds.), Proceedings of the $4^{\text {th }}$ Pronunciation in Second Language Learning and Teaching Conference, Aug. 2013 (pp. 157-166). Ames, IA: Iowa State University.

Volín, J., Uhrinová, M., \& Skarnitzl, R. (2012). The effect of word-initial glottalization on word monitoring in Slovak speakers of English. Research in Language, 12(2), 173-181. DOI: 10.2478/rela-2014-0008

Whitworth, N. (2003). Prevocalic boundaries in the speech of German-English bilinguals. Proceedings of the 15th ICPhS, Barcelona. 1093-1096.

Wiese, R. (1996). The Phonology of German. Oxford: Clarendon Press.

Zsiga, E. (2003). Relearning consonant timing. Studies in Second Language Acquisition, 25(3), 399-432.

Zsiga, E. (2011). External sandhi in a second language: the phonetics and phonology of obstruent nasalization in Korean and Korean-accented English. Language, 87(2), 289-345. 


\section{Appendix}

\begin{tabular}{|l|c|c|}
\hline \multicolumn{1}{|c|}{ Phrase } & Glottalizaed - target onset & Linked - target onset \\
\hline and they asked me & 281 & 258 \\
\hline Bob ate the whole chicken & 178 & 183 \\
\hline Frank showed everyone his new car & 563 & 467 \\
\hline His car always breaks down & 375 & 388 \\
\hline I go every day to the gym & 303 & 254 \\
\hline I saw everything there is to see & 233 & 340 \\
\hline I'll know after the exam & 299 & 246 \\
\hline I'm afraid Alice will be late & 461 & 434 \\
\hline in the end & 258 & 272 \\
\hline The band played excellent songs & 678 & 585 \\
\hline The kids made excellent cookies & 613 & 567 \\
\hline They actually like & 144 & 110 \\
\hline $\begin{array}{l}\text { They earned equal amounts } \\
\text { of money }\end{array}$ & 308 & 371 \\
\hline They had evenings free & 256 & 253 \\
\hline They made everyone stay quiet & 299 & 233 \\
\hline Try each one & 280 & 212 \\
\hline We paid everyone in cash & 347 & 348 \\
\hline
\end{tabular}

